\title{
ACTIVE TRIMMING OF HYBRID INTEGRATED CIRCUITS $\dagger$
}

\author{
P. NÉMETH ${ }^{\dagger}$ and P. KRÉMER \\ $\dagger$ Technical University, Budapest, Hungary. REMIX, Budapest, Hungary
}

(Received November 1, 1982; in final form October 1, 1983)

One of the more important fields of the microelectronics industry is the manufacturing of hybrid integrated circuits.

An important part of the manufacturing process is concerned with the trimming of the hybrid integrated circuits. This article deals with the basic principles of active trimming and introduces a microprocessor controlled trimming machine. By comparing active trimming with passive techniques, it can be shown that the active system has some advantages. This article outlines these advantages.

\section{IMPROVEMENT OF TESTING AND QUALITY CONTROL TASKS IN HYBRID MICROCIRCUIT MANUFACTURE}

The possibility of producing more complicated and reliable hybrid circuits has been achieved by increasing the variety of the materials and components used and by improving their quality. The role and importance of the measuring tasks has increased with the development of hybrid circuits. By analysing the production costs of the hybrid circuits, we can establish that the testing costs are about one third of the total production cost (Figure 1). This proves that the extent of the tests greatly influences the quality and reliability of the hybrid microcircuits and it has an effect on producing

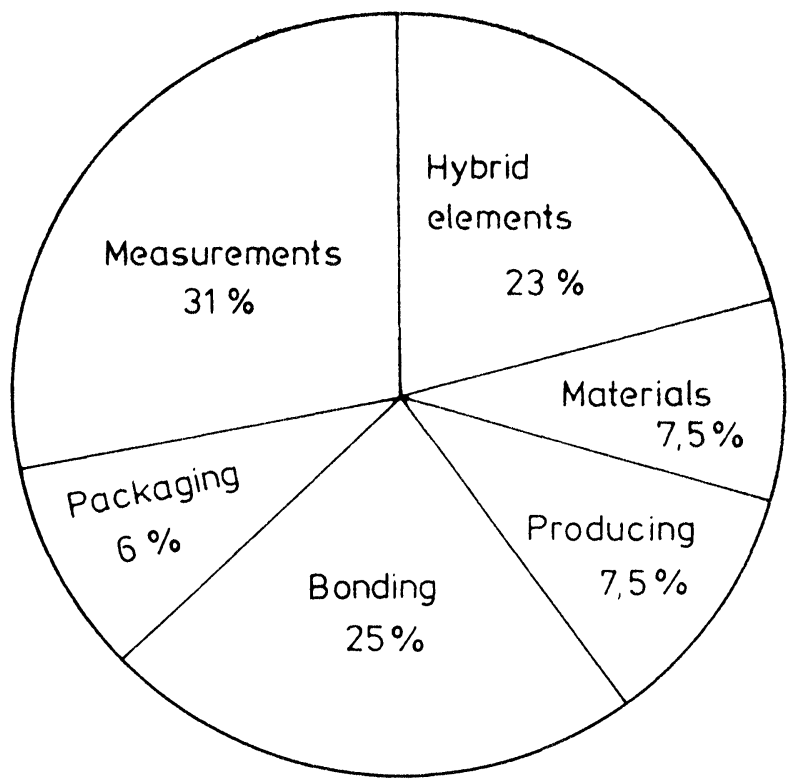

FIGURE 1 Total production costs for hybrid circuits in terms of the various production factors.

\footnotetext{
${ }^{\dagger}$ Paper originally presented at the 5th International Spring Seminar on Electrotechnology held at
} Prenet, Czechoslovakia, 1-4 June, 1982. 
rejects. The most important part of the tests were connected with the trimming operations of hybrid microcircuits. The trimming process usually means the trimming of the basic thin or thick film resistor network.

\section{THE BASIC PRINCIPLES OF TRIMMING THIN OR THICK FILM RESISTOR NETWORKS ${ }^{1}$}

Thin and thick film resistors are still inaccurate after the evaporation and the photolithographic processes. This is caused mainly by the deviations of sheet resistance $R_{\square}$ and the geometrical sizes. This deviation is between $\pm 5 \%$ and $\pm 20 \%$.

High accuracy can be reached only by subsequent adjustment. We can classify the technological procedures according to the parameters which will be changed. Accordingly the trimming process can occur due to the changes in

- the specific resistance

- the thickness of the layer

- the layout pattern

A general table of the trimming technologies available is shown in Figure 2.

The methods, which are based on the changing of the specific resistance, can increase or decrease the specific resistance of the resistors. Thus one can trim resistors which have originally either too large or too small a value.

\begin{tabular}{|c|c|c|c|c|c|c|c|}
\hline \multirow{2}{*}{ Technology } & \multicolumn{2}{|c|}{ Suitable } & \multicolumn{2}{|c|}{$\begin{array}{l}\text { Changing of } \\
\text { resistor value }\end{array}$} & \multicolumn{3}{|c|}{ Trımming method } \\
\hline & $\begin{array}{l}\text { Thin } \\
\text { film }\end{array}$ & $\begin{array}{l}\text { Thick } \\
\text { film }\end{array}$ & Positive & Negative & $\begin{array}{l}\text { Specific } \\
\text { resistance }\end{array}$ & $\begin{array}{l}\text { Thickness } \\
\text { of layer }\end{array}$ & Pattern \\
\hline Thermal & + & - & + & - & + & - & - \\
\hline Electrochemical & - & + & + & + & + & - & - \\
\hline High frequency & - & + & + & + & + & - & - \\
\hline Voltage pulse & + & + & - & + & + & - & - \\
\hline $\begin{array}{l}\text { Mechanical } \\
\text { wearing }\end{array}$ & + & + & + & - & - & + & + \\
\hline Ultrasonic & + & + & + & - & - & + & + \\
\hline $\begin{array}{l}\text { Anodic } \\
\text { oxidization }\end{array}$ & + & - & + & - & - & + & - \\
\hline Wearing beam & - & + & + & - & - & - & + \\
\hline Electroerosion & + & - & + & - & - & - & + \\
\hline Laser beam & + & + & + & - & - & - & + \\
\hline
\end{tabular}

FIGURE 2 General table of trimming technologies. 
The following trimming technologies can achieve this:-

- thermal trimming

- electromechanical trimming

- trimming process using high frequency discharge

- trimming with voltage pulses

One can also change the value of the resistor by changing the thickness of the layer. These methods usually increase the resistor value, so only negative tolerance resistors can be trimmed with these processes. We can trim both thin and thick film resistors with the so called 'mechanical wearing' and ultrasonic methods, but the anodic oxidization method can be used only for trimming of thin film circuits.

The most frequently used and most important trimming methods change the circuit pattern, so that they remove a part of the layer from the substrate, producing nonconductive stripes. As the value of the resistor increases in this case, the process can be used only for trimming negative tolerance resistors. Removing the layer can be done using either mechanical wearing, the ultrasonic method, electroerosion or laser beam technology.

In the electroerosion method ${ }^{2}$ a nibbed needle is moved on the surface of the film using little force and a voltage of about $60 \mathrm{~V}$ is applied between the layer and needle. A micro arc discharge occurs in the immediate vicinity of the needle point. The resistor layer burns out at the contact point, and a non-conducting strip of a width about 10 to $100 \mu \mathrm{m}$ is created.

The main advantage of these methods is that they can be done automatically, and the resistors can be trimmed with high accuracy and reliability. We have developed an equipment at the Department of Electronics Technology of the Technical University, Budapest, which is based on the electroerosion trimming method. It can also be applied to laser beam trimming. ${ }^{3}$

\section{METHODS OF ACTIVE TRIMMING OF HYBRID MICROCIRCUITS}

In so called 'active trimming' we perform the trimming of resistors after inserting the discrete elements, during operation of the electrical circuit. This procedure has some advantages. The most important one is that we measure and trim the output parameter with high accuracy, which is important for the user.

The requirements of active trimming are as follows:-

- the output parameter has to be sensitive to the changing of the resistor.

- the changing of the resistor must not influence the value of other output parameters.

Active trimming usually requires higher level measuring technology and automation than the passive method. Normally we need a trimming method which does not disturb the measuring processes. Therefore, we usually use the laser beam trimming technology.

\section{PRINCIPAL STRUCTURE OF A MICROPROCESSOR CONTROLLED ACTIVE TRIMMING EQUIPMENT}

In the designing of an active trimming apparatus we have to take the following factors 
into consideration:-

- Suitable controlled power supplies have to be assured

- The trimming process has to be automated

- The equipment has to be capable of trimming several parameters of the circuit

- The equipment has to be versatile, and the time for resetting has to be short

Such a fully automated active trimming system has been developed in conjunction with our colleagues at REMIX.

A block diagram of this microprocessor controlled active trimming equipment is shown in Figure 3. The process is controlled by a microprocessor based on a small computer. A laser beam equipment performs the trimming of the resistor network. Programmable power supplies and signal sources perform the controlling of the trimming circuit. We can measure the output parameters, that have to be adjusted with the help of controlled measuring units. The measuring programs and the controllable measuring instruments make possible the simultaneous measuring of different output parameters. Data assembling and storing is also possible. The connection of the instruments is done through the matrix unit. The programmable power supplies and

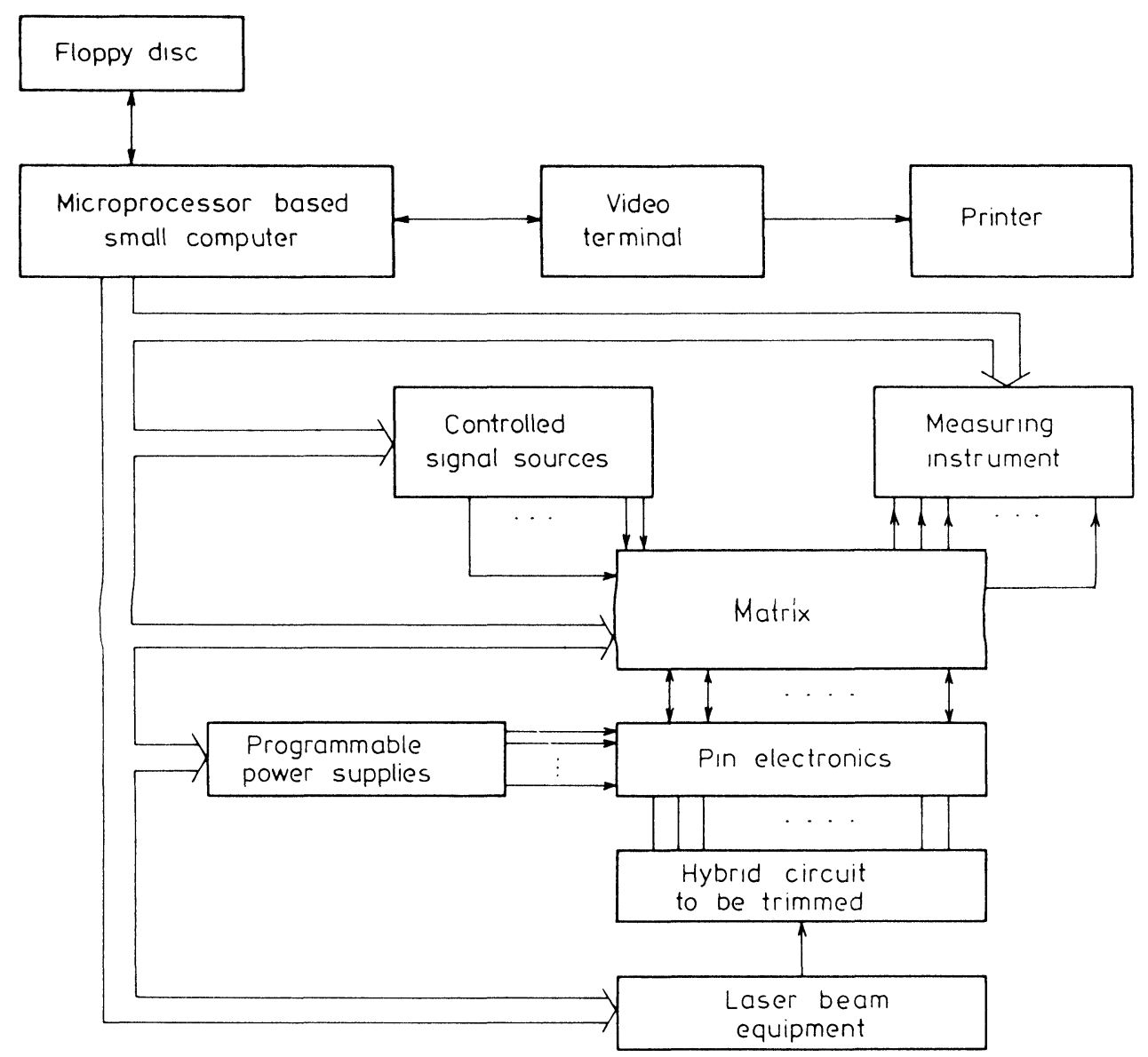

FIGURE 3 Block diagram of an active trimming equipment 
measuring instruments are in communication with the computer through a standard IEC- 625 bus. The control and measuring programs can be stored on a floppy disk, and the results can be displayed on a video-terminal and a printer. The program is suitable for the determination of the statistical data of the trimming parameters.

It is expected that the role and importance of active trimming will increase in the near future, because this method is very productive and the output parameters of hybrid circuits can be trimming with high accuracy.

\section{CONCLUSION}

It has been shown that the basic principle of active trimming is of considerable use for testing hybrid integrated circuits. A microprocessor controlled trimming machine using laser beam technology has been developed and an outline of the total active trimming equipment has been given.

\section{REFERENCES}

1. Hajdú István and Ripka Gábor, "Hibrid integrált áramkörök”, Müszaki Könyvkiadó, Budapest, (1979).

2. Zs. Illyfalvi-Vitéz, "Comparison of Arc Erosive and Laser Beam Trimming of Thin Film Resistors", Electrocomponent Science and Technology, 4, pp 179-183, (1977).

3. Németh Pál, "Hagyományos felépitésü ès mikroprocesszoros Koordinátaasztal vezérlések összehasonlitása", Finommechanika - Mikrotechnika 8, 237-239, (1979). 

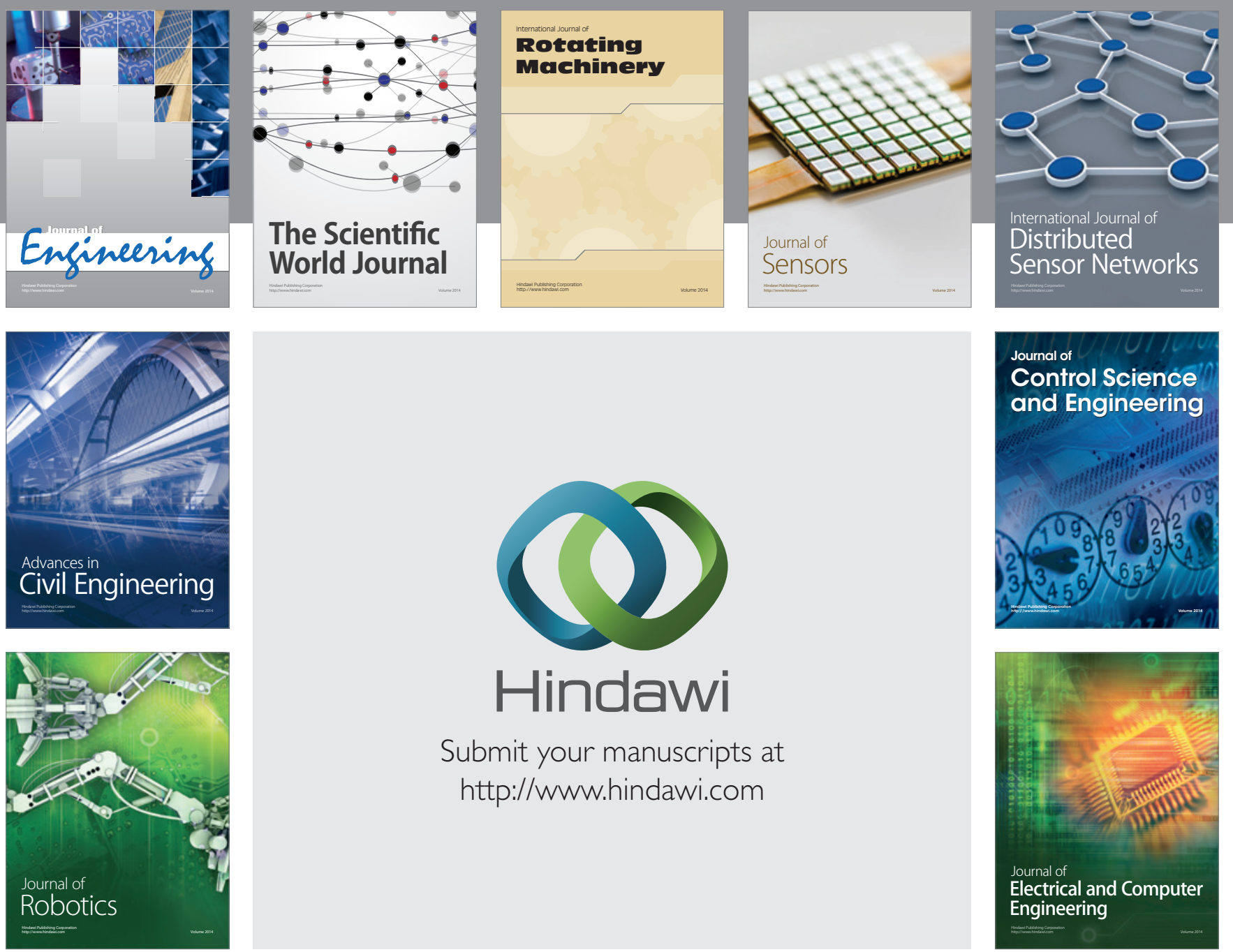

Submit your manuscripts at

http://www.hindawi.com
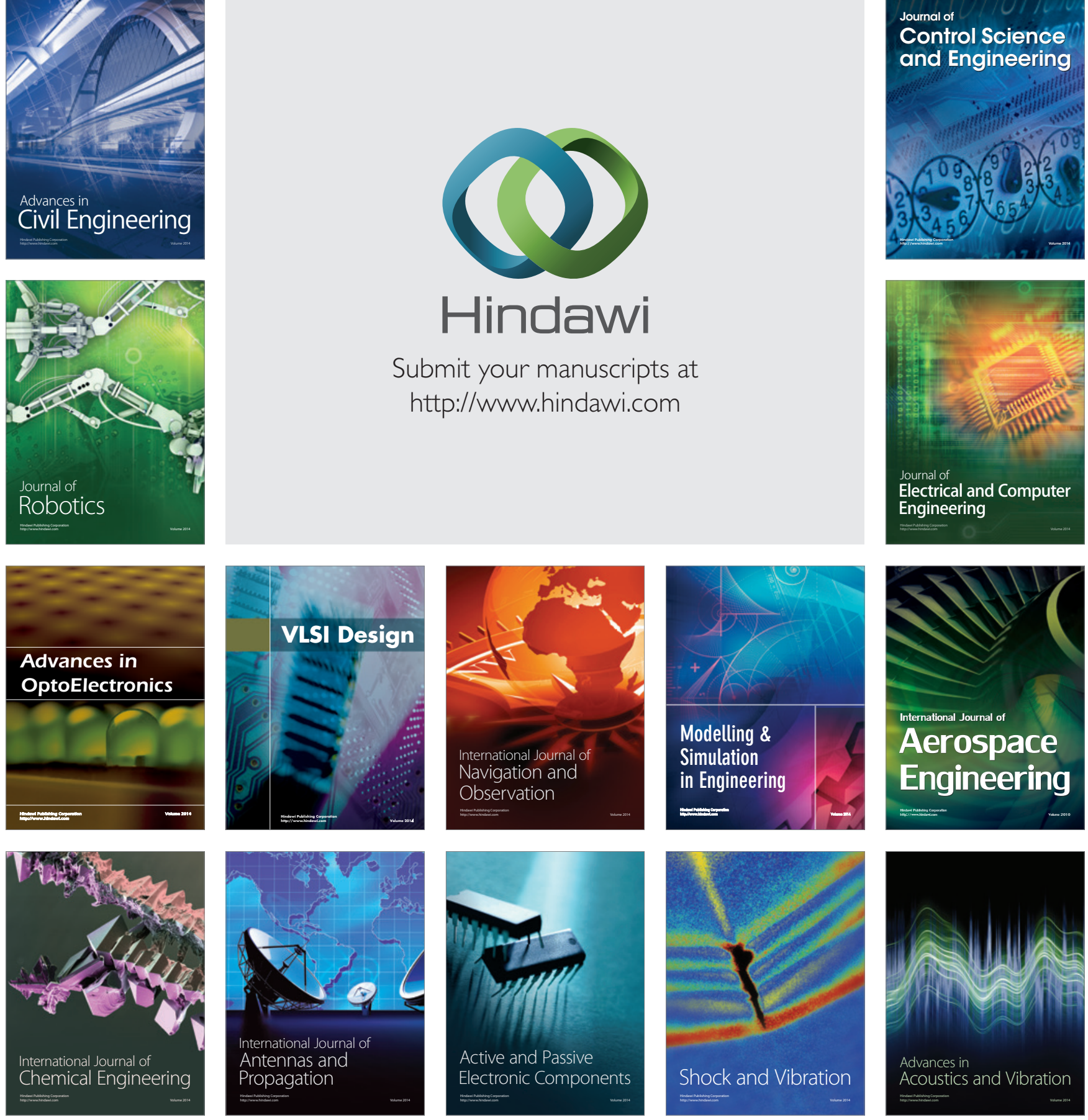